\title{
UPAYA MENINGKATKAN KOMPETENSI PENGGUNAAN MEDIA PEMBELAJARAN DARING (GOOGLE CLASSROOM) MELALUI IN HOUSE TRAINING
}

\author{
Sareh Joko Pitoyo \\ SD Negeri 3 Baturetno UPT Dinas Pendidikan Kecamatan Baturetno Kabupaten Wonogiri \\ Email: jokopitoyosareh@gmail.com
}

\begin{abstract}
Abstrak
Penelitian ini bertujuan untuk meningkatkan Kompetensi guru dalam menggunakan media pembelajaran daring google classroom melalui in house training pada guru SD Negeri 3 Baturetno. Metode penelitian pada penelitian ini menggunakan Penelitian Tindakan Sekolah. Subjek penelitian berjumlah 8 orang guru. Instrumen yang digunakan dalam penelitian yaitu angket dan observasi. Teknik analisis data yang digunakan yaitu triangulasi metode. Sementara tindakan yang diberikan oleh peneliti yaitu berupa pemberian tindakan in house training. Indikator keberhasilan tindakan yaitu Tindakan dinyatakan berhasil apabila 100\% subjek penelitian menunjukkan peningkatan kemampuan menggunakan media pembelajaran daring google classroom pada kategori tinggi. Kondisi awal/pratindakan diperoleh hasil bahwa kemampuan guru menggunakan media pembelajaran daring Google Classroom pada kategori tinggi sebanyak 12,5\%, kategori sedang sebanyak 37,5\%, dan kategori rendah sebanyak 50\%. Hasil tersebut mengindikasikan bahwa perlu adanya perlakuan kepada subjek penelitian. Tindakan pada siklus I menunjukkan hasil bahwa subjek berkemampuan menggunakan media pembelajaran daring Google Classroom pada kategori tinggi sebanyak 50\%, kategori sedang sebanyak 50\%, dan kategori rendah sebanyak 0\%. Tindakan siklus II menunjukkan hasil bahwa subjek berkemampuan menggunakan media pembelajaran daring Google Classroom pada kategori tinggi sebanyak 87,5\%, kategori sedang sebanyak 12,5\%, dan kategori rendah $0 \%$. Tindakan siklus III menunjukkan hasil bahwa 100\% subjek sudah berkemampuan menggunakan media pembelajaran daring Google Classroom pada kategori tinggi sehingga penelitian tindakan sekolah dinyatakan berhasil dan tidak perlu dilanjutkan pada siklus berikutnya. Berdasarkan hasil penelitian dapat disimpulkan bahwa In House Training dapat meningkatkan kemampuan guru menggunakan media pembelajaran daring Google Classroom di Sekolah Dasar Negeri 3 Baturetno.
\end{abstract}

Kata kunci: In House Training, Media Pembelajaran Daring, Google Classroom

\begin{abstract}
This study aims to improve teacher competence in using online learning media google classroom through in-house training for teachers at State Elementary School 3 Baturetno. The research method in this study used School Action Research. The research subjects were 8 teachers. The instruments used in this research are questionnaires and observations. The data analysis technique used is triangulation method. Meanwhile, the action given by the researcher is in the form of providing in-house training. The indicator for the success of the action is that the action is declared successful if 100\% of the research subjects show an increase in the ability to use online learning media google classroom in the high category. The initial/pre-action conditions showed that the teacher's ability to use Google Classroom online learning media was in the high category as much as $12.5 \%$, in the medium category as much as $37.5 \%$, and in the low category as much as 50\%. These results indicate that there is a need for treatment of research subjects. The action in the first cycle showed that the subject was able to use Google Classroom online learning media in the high category by 50\%, in the medium category by 50\%, and in the low category by $0 \%$. The second cycle of action shows that the subject is able to use Google Classroom online learning media in the high category as much as $87.5 \%$, the medium category as much as $12.5 \%$, and the low category 0\%. The third cycle of action showed that 100\% of the subjects were able to use Google Classroom online learning media in the high category so that the school action research was declared successful and did not need to be continued in the next cycle. Based on the results of the study, it can be
\end{abstract}


concluded that In House Training can improve the ability of teachers to use online learning media Google Classroom at State Elementary School 3 Baturetno.

Keywords: In House Training, Online Learning Media, Google Classroom

\section{PENDAHULUAN}

Undang-Undang Nomor 14 Tahun 2005 tentang Guru dan Dosen mengemukakan bahwa guru adalah pendidik profesional dengan tugas utama mendidik, mengajar, membimbing, mengarahkan, melatih, menilai, dan mengevaluasi peserta didik pada pendidikan anak usia dini jalur pendidikan formal, pendidikan dasar, dan pendidikan menengah. Guru di tuntut selalu membuat perencanaan dalam kegiatan pembelajarannya.

Di dalam perencanaan pembelajaran terdapat salah satu elemen penting yang harus dipersiapkan oleh guru untuk memberikan materi kepada siswa yaitu media pembelajaran. Media pembelajaran merupakan sarana yang digunakan oleh guru dalam menyampaikan materi pelajaran kepada siswa dimana materi dapat dikemas dan disajikan secara lebih menarik sehingga diharapkan mampu meningkatkan minat siswa untuk memahami materi yang disampaikan.

Dengan adanya pandemi Covid-19 yang melanda mengharuskan siswa melakukan pembelajaran di rumah. Guru dalam memberikan pembelajaran harus mengubah metode pembelajarannya, dari metode pembelajaran konvensional menjadi metode non tatap muka atau pembelajaran daring. Untuk melakukan pembelajaran daring diperlukan kesiapan dari berbagai pihak dan memerlukan perangkat pendukung. Sistem pembelajaran daring (dalam jaringan) merupakan sistem pembelajaran non tatap muka secara langsung antara guru dan siswa tetapi dilakukan melalui online yang menggunakan jaringan internet (Ruskan, etc 454:2012).

Basori (2017:42) (Nurgiansah \& Sukmawati, 2020) menyatakan bahwa
Pembelajaran Daring adalah pembelajaran yang menggunakan peralatan elektronik jaringan (LAN, WAN, atau internet) untuk menyampaikan materi pembelajaran, interaksi, maupun bimbingan. Guru harus memastikan kegiatan belajar mengajar tetap berjalan, meskipun siswa berada di rumah. Solusinya, guru dituntut dapat mendesain media pembelajaran sebagai inovasi dengan memanfaatkan media daring (online). Guru dapat melakukan pembelajaran daring dengan menggunakan media sosial seperti WhatsApp, Google Kelas, aplikasi zoom ataupun media lainnya sebagai media pembelajaran.

Media pembelajaran adalah alat bantu yang digunakan untuk membangun komunikasi dan interaksi antara guru dan siswa dan proses belajar mengajar. Kata media berasal dari bahasa latin dan merupakan bentuk jamak kata medium yang secara harfiah berarti perantara atau pengantar. Media adalah perantara atau pengantar pesan dari pengirim ke penerima pesan. (Arif S. Sadiman, dkk., 1990: 6) (Nurgiansah, Pratama, et al., 2021).

Umar Suwito (Suharsimi Arikunto, 1993:45) memberi batasan media pembelajaran sebagai berikut: media pembelajaran adalah sarana pembelajaran yang digunakan sebagai sarana untuk mencapai tujuan. Salah satu media pembelajaran daring yang cukup familiar yaitu Google Kelas atau lebih dikenal dengan Google Classroom. Media ini merupakan salah satu fitur yang dimiliki oleh google yang dikhususkan sebagai media untuk memberikan materi pembelajaran kepada siswa. Pada prinsipnya, google classroom menyediakan berbagai macam layanan yang memudahkan guru untuk menyampaikan materi, tugas, presensi, dan juga kuis. 
Dalam satu aplikasi ini guru lebih mudah mengadministrasi proses pembelajaran dan mudah untuk diakses oleh siswa. Guru dapat mengatur waktu untuk memposting presensi, tugas, materi, serta kuis sesuai dengan jadwal yang sudah ditentukan oleh sekolah. Oleh karena itu, hal tersebut memudahkan guru dalam memberikan materi pelajaran secara daring.

Namun, fenomena di lapangan menunjukkan bahwa belum semua guru memiliki kompetensi dan kemampuan untuk menggunakan media pembelajaran daring khususnya google classroom. Hal tersebut dapat dibuktikan dengan hasil observasi yang dilakukan peneliti di SD negeri 3 Baturetno. Dalam hal ini, peneliti adalah kepala sekolah dasar tersebut. Hasil observasi menunjukkan bahwa dari 8 Guru yang mengajar, belum ada yang memiliki kompetensi dalam mengoperasikan google classroom dengan baik. Rata-rata, para guru memiliki keterbatasan yaitu dalam mengoperasikan komputer, belum mengenal aplikasi google classroom dengan baik, serta masih perlu pendalaman dan penyesuaian dengan metode pembelajaran daring yang baru saja digalakkan oleh pemerintah.

Mengacu pada fenomena tersebut, peneliti merancang pelatihan melalui metode In House Training. In House Training berasal dari istilah in house yang berarti dalam rumah dan training berarti pelatihan. Robbins, Stephen P, (2001:282) (Nurgiansah, Hendri, et al., 2021), training atau pelatihan yang dimaksudkan disini adalah pelatihan formal yang direncanakan sendiri secara matang dan mempunyai suatu format pelatihan yang terstruktur. Sementara itu, Gomes (2003:197) menjelaskan bahwa, In House Training adalah setiap usaha untuk memperbaiki performansi pekerja pada suatu pekerjaan tertentu yang sedang menjadi tanggung jawabnya, atau satu pekerjaan yang ada kaitannya dengan pekerjaannya di tempat sendiri. In House Training yaitu sebuat program pelatihan dimana materi, waktu serta tempat pelatihan disesuaikan dengan permintaan dan kebutuhan peserta. Program ini dapat meningkatkan kualitas SDM dan ketentuan peserta dalam IHT minimal 4 orang dan maksimal 15 orang.

Menurut Mustofa Kamil (2013:14) langkah-langkah IHT Model Partisipatif yaitu: 1) Mengadakan perekrutan peserta IHT, 2) Mengidentifikasi sumber, kebutuhan, dan hambatan, 3) Menentukan tujuan umum dan khusus, 4) Menyusun instrument pre dan post tes, 5) Menyusun jadwal, bahan, metode, dan teknik, 6) Mengadakan pelatihan narasumber, 7) Melaksanakan pretest, 8) Melaksanakan proses pelatihan dan 9) Megadakan evaluasi post tes.

Pada penelitian kali ini In House Training merupakan pelatihan yang dilaksanakan secara internal oleh kelompok kerja guru, sekolah atau tempat lain yang ditetapkan sebagai penyelenggaraan pelatihan yang dilakukan berdasar pada pemikiran bahwa sebagian kemampuan dalam meningkatkan kompetensi dan karier guru.

Materi In House Training yang akan dilaksanakan yaitu berkenaan dengan peningkatan kompetensi guru dalam menggunakan media pembelajaran daring yaitu google classroom. Melalui pelatihan ini, guru akan dilatih untuk dapat mengoperasikan aplikasi google classroom dalam mengelola kegiatan pembelajaran secara daring. Sehingga harapannya yaitu dengan dimilikinya kompetensi dalam menggunakan media pembelajaran daring dalam proses pembelajaran maka kegiatan belajar daring siswa akan semakin efektif, efisien dan menyenangkan.

\section{METODE PENELITIAN}

Prosedur penelitian yang akan dilakukan dalam penelitian tindakan 
sekolah ini adalah berbentuk siklus, dan dilaksanakan dengan 3 siklus dimana setiap siklus terdiri dari beberapa tindakan dan pengamatan. Pada akhir siklus diharapkan tercapainya tujuan yang diinginkan. Dalam penelitian tindakan sekolah ini digunakan model Spiral Kemmis dan MC Taggart (Hermawan, 2006: 128) secara berulang-ulang, semakin lama, diharapkan semakin meningkat perubahannya atau pencapaian hasilnya.

\section{Bagan 1. Model Desain Kemmis \& Mc Taggart} (Hermawan, 2006: 128)

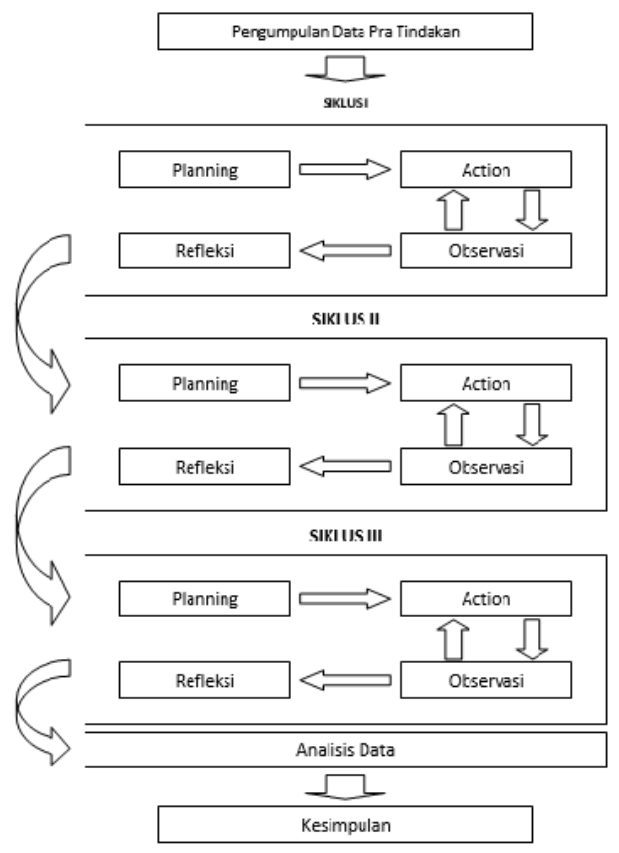

Penelitian ini mengambil tempat di SD Negeri 3 Baturetno pada Semester I Tahun Pelajaran 2018/2019. Penelitian ini dilakukan dalam waktu kurang lebih 6 bulan, dimulai dari bulan Juni s.d Desember 2020. Subjek pada penelitian yaitu adalah guru SD Negeri 3 Baturetno yang berjumlah 8 orang. Teknik pengumpulan data yang digunakan dalam penelitian ini yaitu 1) Angket, 2) Observasi. Uji validitas data pada penelitian ini menggunakan cara trianggulasi data yaitu dengan mengumpulkan data sejenis menggunakan alat pengumpul data yang berbeda. Indikator keberhasilan dalam penelitian ini yaitu: Tindakan dinyatakan berhasil apabila $100 \%$ subjek penelitian menunjukkan peningkatan kemampuan menggunakan media pembelajaran daring google classroom pada kategori tinggi. Peningkatan kemampuan guru menggunakan media pembelajaran daring google classroom dapat dilihat dari perbandingan persentase awal sebelum tindakan penelitian dilakukan dengan persentase setelah tindakan penilitian dilakukan serta berdasarkan kategori kinerja yang ditunjukkan oleh masingmasing subjek penelitian.

\section{HASIL PENELITIAN DAN PEMBAHASAN Hasil Penelitian Kondisi Awal/Pra Tindakan}

Survei awal tersebut dilakukan peneliti pada tanggal 22 sampai dengan 23 Juni 2020 dengan cara menyebarkan angket dan melakukan observasi terhadap subjek penelitian.

Tabel 1. Hasil pengerjaan angket dan observasi Kondisi Awal/Pra Tindakan

\begin{tabular}{|c|c|c|c|c|}
\hline Subjek & Angket & Kategori & Observasi & Kategori \\
\hline 1 & 59 & Rendah & 20 & Rendah \\
\hline 2 & 80 & Sedang & 25 & Sedang \\
\hline 3 & 50 & Rendah & 17 & Rendah \\
\hline 4 & 88 & Rendah & 18 & Rendah \\
\hline 5 & 75 & Sedang & 30 & Sedang \\
\hline 6 & 85 & Sedang & 29 & Sedang \\
\hline 7 & 111 & Tinggi & 40 & Tinggi \\
\hline 8 & 48 & Rendah & 15 & Rendah \\
\hline
\end{tabular}

Hasil angket dan observasi tersebut menunjukkan bahwa dari kemampuan aplikasi TIK dalam pembelajaran pada kategori rendah terdapat 4 subjek (50\%), kategori sedang terdapat 3 subjek $(37,5 \%)$, dan kategori tinggi terdapat 1 subjek $(12,5 \%)$. 


\section{Siklus I}

Pelaksanaan siklus I dilaksanakan selama dua hari yaitu pada tanggal 29 dan 30 Juni 2020. Pada siklus I ini dilakukan dengan langkah-langkah:

a. Perencanaan yang meliputi pengamatan awal, membuat materi pelatihan dan menentukan narasumber.

b. Pelaksanaan yang meliputi merekrut peserta pelatihan, menentukan tujuan, membuat instrument pre dan post test, membuat jadwal dan melaksanakan pelatihan serta evaluasi.

c. Observasi meliputi peneliti menyebar instrument angket dan dianalisis hasilnya serta melakukan observasi selama 1 minggu.

Tabel 2. Hasil Pengerjaan Angket dan Observasi Siklus I

\begin{tabular}{|c|c|c|c|c|}
\hline Subjek & Angket & Kategori & Observasi & Kategori \\
\hline 1 & 90 & Sedang & 30 & Sedang \\
\hline 2 & 100 & Tinggi & 39 & Tinggi \\
\hline 3 & 90 & Sedang & 25 & Sedang \\
\hline 4 & 89 & Sedang & 24 & Sedang \\
\hline 5 & 110 & Tinggi & 40 & Tinggi \\
\hline 6 & 111 & Tinggi & 42 & Tinggi \\
\hline 7 & 118 & Tinggi & 39 & Tinggi \\
\hline 8 & 89 & Sedang & 29 & Sedang \\
\hline
\end{tabular}

d. Refleksi

Mengacu pada indikator keberhasilan yang telah ditetapkan oleh peneliti bahwa, "Tindakan dinyatakan berhasil apabila $\quad 100 \%$ subjek penelitian menunjukkan peningkatan kemampuan menggunakan media pembelajaran daring google classroom pada kategori tinggi". Maka hasil refleksi dapat disimpulkan bahwa baru $50 \%$ subjek yang menunjukkan kemampuan menggunakan media pembelajaran daring google classroom pada kategori tinggi. Oleh karena itu perlu adanya tindakan lanjutan pada siklus berikutnya yaitu siklus II.

\section{Siklus II}

Pelaksanaan siklus II dilaksanakan pada tanggal 13 dan 14 Juli 2020. Pada siklus II dilakukan langkah-langkah:

a. Perencanaan yang meliputi pengamatan lanjutan, dan membuat materi pelatihan.

b. Pelaksanaan, pada tahap ini dilakukan pelatihan, pre dan post test, serta evaluasi.

c. Observasi, meliputi menyebar instrument angket dan dianalisis hasilnya. Observasi dilakukan 1 minggu.

Tabel 3. Hasil Pengisian Angket dan Observasi Siklus II

\begin{tabular}{|c|c|c|c|c|}
\hline Subjek & Angket & Kategori & Observasi & Kategori \\
\hline 1 & 115 & Tinggi & 37 & Tinggi \\
\hline 2 & 118 & Tinggi & 41 & Tinggi \\
\hline 3 & 116 & Tinggi & 38 & Tinggi \\
\hline 4 & 100 & Tinggi & 39 & Tinggi \\
\hline 5 & 116 & Tinggi & 45 & Tinggi \\
\hline 6 & 118 & Tinggi & 46 & Tinggi \\
\hline 7 & 119 & Tinggi & 44 & Tinggi \\
\hline 8 & 90 & Sedang & 35 & Sedang \\
\hline
\end{tabular}

d. Refleksi

Mengacu pada indikator keberhasilan yang telah ditetapkan oleh peneliti bahwa, "Tindakan dinyatakan berhasil apabila $100 \%$ subjek penelitian menunjukkan peningkatan kemampuan guru menggunakan media pembelajaran daring google classroom pada kategori tinggi". Maka hasil refleksi dapat disimpulkan bahwa baru 87,5\% subjek yang menunjukkan kemampuan menggunakan media pembelajaran daring google classroom pada kategori tinggi. Oleh karena itu perlu adanya tindakan lanjutan pada siklus berikutnya yaitu siklus III.

\section{Siklus III}

Pelaksanaan siklus III dilaksanakan pada tanggal 3 dan 4 Agustus 2020. Langkah-langkah yang dilaksanakan pada tahap ini yaitu: 
a. Perencanaan meliputi membuat pengamatan lanjutan dan membuat rencana materi pelatihan.

b. Pelaksanaan meliputi kegiatan pelaksanaan pelatihan, pre dan post test serta evaluasi.

c. Observasi meliputi menyebarkan instrument angket dan analisis hasilnya. Observasi dilakukan selama 1 minggu.

Tabel 4. Hasil Pengisian Angket dan Observasi Siklus III

\begin{tabular}{|c|c|c|c|c|}
\hline Subjek & Angket & Kategori & Observasi & Kategori \\
\hline 1 & 119 & Tinggi & 37 & Tinggi \\
\hline 2 & 119 & Tinggi & 41 & Tinggi \\
\hline 3 & 118 & Tinggi & 38 & Tinggi \\
\hline 4 & 113 & Tinggi & 39 & Tinggi \\
\hline 5 & 118 & Tinggi & 45 & Tinggi \\
\hline 6 & 118 & Tinggi & 46 & Tinggi \\
\hline 7 & 120 & Tinggi & 44 & Tinggi \\
\hline 8 & 115 & Tinggi & 35 & Tinggi \\
\hline
\end{tabular}

d. Refleksi

Mengacu pada indikator keberhasilan yang telah ditetapkan oleh peneliti bahwa, "Tindakan dinyatakan berhasil apabila $100 \%$ subjek penelitian menunjukkan peningkatan kemampuan menggunakan media pembelajaran daring google classroom pada kategori tinggi". Maka hasil refleksi dapat disimpulkan bahwa tindakan dinyatakan berhasil dan tidak perlu dilanjutkan pada siklus berikutnya.

\section{Pembahasan}

Penelitian ini merupakan penelitian tindakan sekolah yang terdiri dari tiga siklus yaitu siklus I, siklus II dan siklus III, dengan tindakan yang berupa pelatihan dalam bentuk In House Training. Tujuan penelitian ini adalah untuk meningkatkan kemampuan guru menggunakan media pembelajaran daring google classroom di Sekolah Dasar Negeri 3 Baturetno Kecamatan Baturetno Kabupaten
Wonogiri. Hasil penelitian yang telah dilaksanakan oleh peneliti diperoleh perubahan positif yang signifikan yaitu berupa peningkatan kemampuan menggunakan media pembelajaran daring google classroom pada subjek penelitian dari kondisi awal/pratindakan, siklus I, siklus II, dan siklus III.

Hasil pengerjaan angket dan observasi awal sebelum tindakan dapat dikemukakan bahwa, dari 8 subjek penelitian hanya ada 1 yang menunjukkan kemampuan menggunakan media google classroom pada kategori tinggi. Oleh karena itu, peneliti membuat perencanaan pemberian perlakuan pada tahap selanjutnya yang disebut dengan siklus I. Pada siklus I, hasil refleksi diperoleh 50\% subjek yang menunjukkan kemampuan menggunakan media pembelajaran daring google classroom pada kategori tinggi.

Oleh karena itu perlu adanya tindakan lanjutan pada siklus berikutnya yaitu siklus II. Siklus II, hasil refleksi diperoleh $87,5 \%$ subjek yang menunjukkan kemampuan menggunakan media pembelajaran daring google classroom pada kategori tinggi. Oleh karena itu perlu adanya tindakan lanjutan pada siklus berikutnya yaitu siklus III. Pada siklus III, hasil refleksi $100 \%$ subjek menunjukkan peningkatan kemampuan menggunakan media pembelajaran daring google classroom pada kategori tinggi dan siklus berikutnya tidak perlu dilakukan.

\section{KESIMPULAN}

Kesimpulan dari penelitian ini adalah In House Training dapat meningkatkan kemampuan guru menggunakan media pembelajaran daring Google Classroom di Sekolah Dasar Negeri 3 Baturetno, yaitu: 1) Kondisi awal/pratindakan diperoleh hasil bahwa kemampuan guru menggunakan media pembelajaran daring Google Classroom pada kategori tinggi sebanyak 12,5\%, 
kategori sedang sebanyak 37,5\%, dan kategori rendah sebanyak 50\%. 2) Tindakan pada siklus I menunjukkan kemampuan menggunakan media pembelajaran daring Google Classroom pada kategori tinggi terdapat 50\% subjek, kategori sedang terdapat $50 \%$ subjek, dan kategori rendah terdapat $0 \%$ subjek. 3) Tindakan siklus II menunjukkan kemampuan menggunakan media pembelajaran daring Google Classroom pada kategori tinggi terdapat 87,5\% subjek, kategori sedang terdapat 12,5\% subjek, dan kategori rendah terdapat $0 \%$ subjek. 4) Tindakan siklus III menunjukkan hasil bahwa $100 \%$ subjek sudah berkemampuan menggunakan media pembelajaran daring Google Classroom pada kategori tinggi sehingga penelitian tindakan sekolah dinyatakan berhasil dan tidak perlu dilanjutkan pada siklus berikutnya.

\section{DAFTAR PUSTAKA}

Abdul Kadir. 200. Pengenalan Sistem Informasi. Yogayakarta: Andi.

Danim, Sudarwan. 2012. Motivasi Kepemimpinan dan Efektivitas Kelompok. Jakarta: Rineka Cipta.

Daryanto. 2005. Evaluasi Pendidikan. Jakarta: Rineka Cipta.

E. Mulyasa. 2010. Kurikulum Tingkat Satuan Pendidikan (KTSP). Bandung: PT. Remaja Rosdakarya.

Gomes, Faustino Cardoso. 2003. Manajemen Sumber Daya Manusia. Jakarta: Andi Offset.

Harjanto. 2005. Perencanaan Pengajaran. Jakarta: Rineka Cipta.

Hermawan, A. 2006. Metode Penelitian. Jakarta: PT. Gramedia Widia Sarana. Indonesia.

Isjoni dan Mohd. Arif Ismail. 2008. Model-model Pembelajaran Mutakhir. Yogyakarta: Pustaka Pelajar.

Jamal Ma'mur Asmani. 2011. Buku Panduan Internalisasi Pendidikan Karakter di Sekolah. Jogjakarta: Diva Press.

Mustofa Kamil. 2012. Andragogi. Bandung: UPI.

Nasution. S. 2011. Berbagai Pendekatan Dalam Proses Belajar Mengajar. Jakarta: PT. Bumi Aksara.

Noe, Hollenbeck, Gerhart, Wright. 2003. Human Resource Management. International Edition. Jakarta: MC GrawHill.

Nurgiansah, T. H., Hendri, \& Khoerudin, C. M. (2021). Role Playing Dalam Pembelajaran Pendidikan Pancasila dan Kewarganegaraan. Jurnal Kewarganegaraan, 18(1), 56-64. https://doi.org/10.24114/jk.v18i1.22597

Nurgiansah, T. H., Pratama, F. F., \& Iman, A. S. (2021). Penelitian Tindakan Kelas Dalam Pendidikan Kewarganegaraan. Jurnal Pendidikan Pancasila Dan Kewarganegaraan, 2(1), 10-23.

Nurgiansah, T. H., \& Sukmawati. (2020). Tantangan Guru Pendidikan Kewarganegaraan Di Masa Adaptasi Kebiasaan Baru. Jurpis: Jurnal Pendidikan Ilmu Sosial, 17(2), 139-149.

Robbins, Stephen P. 2001. Perilaku Organisasi: Konsep, Kontroversi, Aplikasi, Jilid. 1, Edisi 8. Jakarta: Prenhallindo.

Rudi Susilana dan Cepi Riyana. 2009. Media Pembelajaran: Hakikat, Pengembangan, Pemanfaatan, dan Penilaian. Bandung: CV Wacana Prima.

Rusman. 2011. Pembelajaran Berbasis Teknologi Informasi dan. Komunikasi: Mengembangkan Profesionalisme Guru. Jakarta: Rajawali.

Sudarwan Danim. 1994. Transformasi Sumber Daya Manusia. Jakarta: Bumi Aksara. 
Sujoko Alfaris. (2012). Peningkatan Kemampuan Guru Mata Pelajaran Melalui In House Training. Jurnal Pendidikan Penabur. No.18 tahun ke-11/Juni. Diakses dari www.bpkpenabur.or.id tanggal 27 Juni 2018.

Sumiati \& Asra. 2009. Metode Pembelajaran. Bandung: CV Wacana Prima.

Supriyanto, Agus. (2013). Pedoman Identifikasi Pemanduan Bakat Istimewa. Yogyakarta: Fakultas Ilmu Keolahragaan UNY Yogyakarta.

Suryosubroto. 1990. Tatalaksana Kurikulum. Jakarta: Rineka Cipta.

Sutarman. 2009. Pengantar teknologi Informasi. Jakarta: Bumi Aksara.

Syaiful Bahri Djamarah. 2006. Strategi Belajar Mengajar. Jakarta: PT Rineka. Cipta.

Syaiful Sagala. 2011. Konsep dan Makna Pembelajaran. Bandung: Alfabeta.

Undang-undang RI No.20 tahun 2003.tentang sistem pendidikan nasional. Jakarta: Depdiknas 